\title{
No Brasil de hoje é possível manter a tradicional cultura dos quilombolas?
}

\section{In today's Brazil, is it possible to maintain the traditional quilombola culture?}

\author{
Eleno Marques de Araújo ${ }^{1 *}$, Thaís Alves de Souza Aires Vilela ${ }^{1}$, Vania Maria \\ de Oliveira Vieira ${ }^{2}$, Nilton Caetano Vilela Filho ${ }^{1}$
}

\begin{abstract}
RESUMO
Este texto foi desenvolvido com base no atual cenário brasileiro, considerando as críticas e ideias de algumas obras de autores que publicaram seus trabalhos nos últimos anos, em especial após o DECRETO No 4.887, DE 20 DE NOVEMBRO DE 2003, e da Lei no 10.639, de 9 de janeiro de 2003, que estabelece as diretrizes e bases da educação nacional, com ênfase na comunidade dos quilombos brasileiros. Buscamos trazer a problemática que gira em torno da qualidade do ensino do quilombo Cedro, no município de MineirosGO, principalmente daqueles que ainda residem em terras te preservação quilombola.
\end{abstract}

Palavras-chave: Cultura; Educação quilombola; Raça.

\section{ABSTRACT}

Abstract: This text was developed based on the current Brazilian scenario, considering the criticisms and ideas of some works by authors who have published their work in recent years, especially after DECREE No. 4.887, OF NOVEMBER 20, 2003, and Law no. 10.639, of January 9, 2003, which establishes the guidelines and bases for national education, with an emphasis on the Brazilian quilombo community. We seek to bring up the issue that revolves around the quality of education in the Cedro quilombo, in the municipality of Mineiros-GO, mainly for those who still reside in quilombola preservation lands.

Keywords: Culture. Quilombola education. Race.

\footnotetext{
${ }^{1}$ Professor titular na UNIFIMES. Doutorando no Programa de Pós-Graduação em Ciências da Educação no CIA-Universidad del Sol em Asunción - PY; 1 Bolsista do projeto de pesquisa e acadêmica do sétimo período do curso de Direito; 1 professor mestre e adjunto.

${ }^{2}$ Doutora e professora no Programa de Pós-Graduação em Educação na UNIUME.
} 


\section{INTRODUÇÃO}

Ao longo da composição deste texto surgiram indagações, e uma reflexão saltouse pelo pensamento, de forma a questionar por que que todas as vezes que entra em pauta discursões sobre "beneficiar" a comunidade negra, geram tantas repercussões negativas na sociedade? Todavia, esta interrogação foi respondida com leituras e aprofundamento na história das comunidades quilombolas, mais especificamente da comunidade do Cedro, em Mineiros. O que ficou evidente durante a busca incansável por respostas, é que o que aprendemos durante toda nossa vida, são apenas a versão contada do ponto de vista do narrador. A verdade é que por muitos anos, o Brasil criou uma imagem destorcida de que não existe descriminação no país, que os brasileiros são um povo harmônico e acolhedor. Aqui no Brasil, a mistura de "raças" faz parte do DNA de cada brasileiro, e que não há um por que de ter a consciência pesada, pois os povos indígenas e Afrobrasileiros já foram compensados o suficiente, com leis e políticas públicas em seu favor. No entanto, a nosso ver, estas justificativas servem apenas para tentar justificar as barbaridades, se é que exista alguma possibilidade de justificação, e consequentemente só serve para manipular a situação, em favor da elite dominadora.

Dessa forma, pensamos que, se existem as leis, elas devem ser cumpridas, além do mais, não surgiram do nada, e infelizmente, se não fosse por elas, embora elas não são suficientes, talvez as pessoas indígenas e afro-brasileiras continuariam até os dias de hoje excluídas da "sociedade civilizada". Nos referimos à civilização pois é o que estamos comumente acostumados em ouvir, e esta realidade até parece ser piada, no sentido em que não somos tão civilizados assim. O exemplo mais claro dessa "não-civilização" são as práticas raciais e xenofóbicas que acontecem na sociedade brasileira, de forma quase generalizada, é o que alguns autores denominam de racismo à brasileira, racismo estrutural ou ainda racismo velado.

A organização do movimento negro foi o primeiro passo para a conquista do direito de igualde social, sendo assim, certamente é "anterior à discussão sobre as cotas ou à ação afirmativa que tem apenas uma dezena de anos" (KABENGELE, 2015, p. 24). Daí, surge a importância do estudo das culturas indígenas e afro-brasileiras ainda nos primeiros anos de ensino do aluno. Já que, infelizmente essa luta, embora, iniciada a muito tempo, ainda não acabou, e precisa ser lembrada e colocada em prática todos os dias. No Brasil, foi construída uma visão erradamente sobre os quilombos. Tudo isso graças as heranças ideológicas hostis e ignorantes, herdadas por nossas famílias. 
As comunidades quilombolas, por muitos anos, foram excluídas da "sociedade" pelo "povo branco". Estes, consideravam, em se tratando dos negros, que se tratava de uma "raça". Assim, como na natureza animal, as raças dos diversos animais possuem determinados grupos ou espécies, e normalmente não se misturam, os brancos também não queriam se misturar aos negros. Apesar de estarmos em pleno século XXI, esta ideologia ainda é manifestada em muitas pessoas. Por outro lado, muitos descendentes afro-brasileiros, os maiores prejudicados e que sofrem com a mediocridade e falsa ideia de que são realmente, diferentes, "inferiores", e dessa forma, incapazes de fundir-se com os "brancos".

Como diz o provérbio popular: "uma mentira contada mais de uma vez se torna verdade". Nesse sentido, faz-se necessário um pensamento sutil, para perceber que em muitos casos, da mesma forma que os brancos se sentem superiores aos negros, a reciproca também pode ser verdadeira, isto é, os negros se sentem realmente diminuídos em comparação aos brancos. Ironicamente este sentimento é resultado da história contada pela cultura dominante, que subjugou os povos negros trazidos à força do continente africano e relegados em primeiro momento à escravidão, e depois posto às margens da sociedade brasileira.

Toda esta problemática deveria ter servido como aprendizado para a humanidade toda, na superação do preconceito e do racismo, porém, o que se vê é a intensificação e a discriminação das pessoas, com o critério de "raças". A propósito, o termo "raça já traz um julgamento hierárquico, quanto à sua suposta classificação. Segundo Kabengele (2015) o conceito é "uma classificação pseudocientífica rejeitada pelos próprios cientistas da área biológica". Segundo ela, o racismo é o maior problema, e é uma forma de justificar a discriminação, motivada pela suposta hierarquia branca. A autora, complementa dizendo que hoje em dia o preconceito já não é apenas baseado no conceito de raça, mais sim, pelos estereótipos que ao longo dos séculos foram sendo impostos aos negros. No entanto, o que mais importa agora é entender a problemática e apontar soluções, de maneira que a sociedade possa superar esse problema social que durante muito tempo enfrenta, com trágicos resultados para os afro-brasileiros.

Posto isto, embora exista inúmeras barreiras em torno da igualdade social da comunidade negra, no Brasil, nosso enfoque persiste somente no aspecto da educação, que hoje é um direito de todos e dever do Estado e da família em proporcionar o ensino à todas as pessoas. Este direito está previsto na Constituição de 1988 e na Lei de Diretrizes 
e Bases da Educação Nacional. Antes o ensino era proibido para todos, com base em leis ou até mesmo crenças religiosas. Acreditamos que a igreja era usada em seus discursos justificando tais ato de exclusão dos negros da sala de aula. Por outro lado, havia também interesses próprios dos burgueses em ter mão de obra escrava. Todavia, para chegar a uma conclusão é necessário pontuar alguns obstáculos que impedem o aprendizado dos afrodescendentes.

Contudo, é importante comentar um pouco sobre o quilombo do cedro, localizado no município de Mineiros região sudoeste de Goiás, pois as informações trazidas para o trabalho não deixam de refletir sobre parte da história dessa região.

A comunidade do Cedro é um exemplo de luta e superação. A mesma, "teve como fundador Francisco Antônio de Morais, apelidado "Chico Moleque", que comprou sua liberdade em uma parte da Fazenda Flores do Rio Verde, no ano de 1885, e naquele local se constituiu a comunidade, existente ainda na mesma região" (FREITAS; LUCIANO E; SILVA, 2021, p. 2), segundo os autores já mencionado, Chico Moleque, foi um escravo vindo de Minas Gerais, por volta de 1850. Atualmente a comunidade tem uma população de 69 famílias que reside no local. Apesar do lapso temporal a terra, não estar ainda titularizada pelo governo, isto é, oficialmente não existe escritura pública do quilombo cedro. Este é um dos problemas que muitos quilombos brasileiros ainda enfrentam, pois o fato de não poderem estar assentados em uma reserva legal desmotiva-os desanimando em seguir com a luta de preservar suas culturas e tradições ancestrais.

Destacamos a importância de levar este conhecimento histórico para as gerações futuras, e não somente isto, mas o principal desafio parecer ser como incentivar a preservação e a sobrevivência das culturas quilombolas para que não se perca no esquecimento.

Propomos como objetivo geral para nos embasar na composição deste texto discutir os pontos principais entorno da problemática da educação quilombola e da cultura afro-brasileira. Como objetivos específicos estabelecemos: pontuar a problemática que os quilombolas enfrentam na luta contra o preconceito da sociedade; entender os motivos que levam os mesmos a abandonarem suas terras; explicar por que os decretos e leis não funcionam como estão previstos na Legislação e finalmente; comentar sobre as políticas públicas que são criadas para sanar os obstáculos que englobam as comunidades.

\section{Metodologia}


A metodologia utilizada para a elaboração deste texto, resultado da pesquisa de iniciação científica da Unifimes, foi a revisão literária e teve como fundamento teórico os artigos literários, e também, informações de telejornais e revistas importantes, bem como,

publicações em sites do governo do Estado de Goiás, no site da Comissão Pro-Índio de São Paulo entre outros.

\section{Referencial teórico}

Atualmente um dos maiores obstáculos em manter a tradição culturalista da comunidade negra está na dificuldade de acesso à educação com componentes curriculares para as disciplinas afro-brasileiras. "Acredita-se que essa nova pedagogia possa contribuir na construção de uma cultura de paz e no fim das guerras entre deuses, religiões e culturas". (KABENGELE, 2015, p. 21).

Todavia, para que isso de fato torne uma realidade, é preciso mais do que apenas discursos demagógicos do governo e das instituições públicas e privadas de ensino. Discursos estes, como o que foi apregoado pela primeira-dama Gracinha Caiado, que disse que "passados tantos anos, a abolição da escravatura no país ainda não acabou com o racismo na sociedade brasileira e que o Governo de Goiás seguirá contribuindo para a superação da intolerância racial", (Secretaria de Estado de Desenvolvimento SocialGoverno do Estado de Goiás, 2019, p. 1). Sem porém apontar de forma clara e concreta quais serão as medidas contributivas do governo do Estado de Goiás para tal superação.

À vista disso, o Estado, em especial o de Goiás, deveria se preocupar mais em levar ensino de qualidade para os que ainda vivem em terras de preservação quilombola, pois estes, são prejudicados pela falta de escolas dentro de seus quilombos. Quando já existem escolas nos quilombos, elas não oferecem o ensino completo, muitas vezes por falta de estruturas adequadas. Neste sentido, o problema é que, como na maioria das vezes, essas escolas são oferecidas pelo munícipio da região. Uma vez que, como previsto em lei, o município é responsável apenas pelo ensino fundamental. Daí que muitos jovens quilombolas não conseguem concluir seus aprendizados, como ensino médio e muita vezes nem o ensino fundamental.

Em relação a este assunto, de acordo com um trabalho realizado pela Instituição de ensino da UNIFIMES, sobre a comunidade do Cedro no município de Mineiros Goiás, é possível confirma o que foi escrito anteriormente, sobre o ensino nos quilombos, pois segundo mostra tal pesquisa, a taxa de alfabetização dessa comunidade é de $92 \%$, não é 
ruim, no entanto, esses dados são exclusivos para a alfabetização, o que não ocorre com os demais ensinos, principalmente com o ensino médio.

Da escolaridade dos cedrinhos observa-se na pesquisa de Thiago $92 \%$ alfabetizados e 7\% não alfabetizados, com o nível de escolaridade dos chefes de família variando da seguinte forma: [...] a média de escolaridade é o ensino fundamental incompleto, $59,2 \%$ com ensino fundamental incompleto, $3,7 \%$ com ensino fundamental completo, $18,6 \%$ com ensino médio incompleto, $3,7 \%$ com ensino médio completo e $7,4 \%$ com ensino superior completo. (THIAGO, 2011, p. 34 apud FREITAS; LUCIANOE E; SILVA, 2021, p. 2).

Um outro problema encontrado nesta comunidade, além da falta de escola, é o abandono do poder público, em fornecer uma qualidade de vida digna para essas pessoas que lutam para manter o estilo de vida de seus ancestrais. Significando que aqueles que possuem terras em locais esquecido pelo governo, são, de certa forma, obrigados a abandona-las, em busca de uma qualidade de vida melhor para eles e para seus filhos. Como explica Freitas; Luciano e Silva (2021, p. 2): “As dificuldades de se obter trabalho e renda no local, e ainda a falta de infraestrutura, como a inexistência de asfalto nas estradas, falta de coleta de lixo, esgoto, e ainda a ausência de assistência médica e escolas/creches, levando à venda das terras e êxodo para a cidade."

Por consequência, o resultado do capitalismo e da industrialização, é o caminho menos complexo, e sendo a cidade de Mineiros considerada fonte de empregabilidade devido o grande número de empresas instaladas no município, a comunidade do Cedro busca "a prestação de serviços no município de Mineiros, trabalhando em empresas e indústrias". (FREITAS; LUCIANOE; SILVA, 2021, p. 7).

Isto nos leva a pensar que a modernidade da sociedade fez os quilombos obsoletos, incapazes de manter suas tradições culturais. Mas, a verdade, é que o aparente fracasso desses grupos é resultado, da discriminação e do abandono imposto pela sociedade. E infelizmente a falta de terras demarcadas e documentadas para os quilombolas, é um obstáculo mesmo após o Decreto $n^{\circ} 4.887$, de 20 de novembro de 2003, que foi estabelecido na época, pelo então presidente da República, Luiz Inácio Lula Da Silva, que reconhece o Cedro como comunidade quilombola.

Com a mudança de governos, as comunidades quilombolas atualmente enfrentam novamente o descaso da União e dos Estados, deste modo, confirmando esse abandono, o "governo de Jair Bolsonaro não titulou um centímetro sequer de Terra Quilombola em 2021”, foi o que mostrou o artigo publicado pela Comunidade pró-índio de São Paulo, 
(2021, p. 1). Significando dessa forma, o desinteresse total do Poder Público em contribuir para a continuidade das tradições culturais do povo negro no Brasil.

Isto posto, em consequência, essas culturas vão se apagando da sociedade. Embora a sociedade seja constituída por maior parte de afro-brasileiros, o modo de vida dos brancos influencia-os, fazendo com que esses grupos, apesar de formar um povo culturalista, seja vencido, graças a negação que a sociedade tem praticado em relação aos seus costumes e principalmente pela sua cor de pele. Percebe-se que as políticas públicas em prol dos afrodescendentes ainda é muito precária, principalmente na educação e na preservação da história do povo negro no Brasil, cabe a eles, bem como a todas as pessoas bem intencionadas, não se satisfazerem com o que é oferecido pelos governos estaduais e federal, mas seguirem lutando por novas políticas afirmativas.

Como relatado por RIBEIRO, em sua Tese de Doutorado pela Universidade Federal de São Carlos

\begin{abstract}
As pesquisas que tiveram como foco de análise as relações raciais em territórios/ comunidades de predominância afrodescendentes sejam elas urbanas (bairros) ou rurais, mostram que nestes espaços também as relações raciais são complexas, mostram que a despeito de terem consciência do seu pertencimento étnico-racial, e que neste espaço são maioria, também percebem a negação pela sociedade brasileira de seu grupo e procuram com isso se comportar como brancos. Algumas mostram por outro lado um grande potencial de mobilização no sentido de armar e legitimar os valores negros. (RIBEIRO, 2005, p. 180-181).
\end{abstract}

Com isso, é como se uma grande muralhava rompesse-se aos poucos, pois, sabese que os quilombolas no Brasil têm uma história de luta e resistência política desde que os negros fugindo de seus senhores, iniciaram sua organização na forma dos quilombos.

A respeito da educação, em especial da população do Cedro, segundo pesquisas realizadas na comunidade no ano de 2010, mostrou a fragilidade das escolas em atender as necessidades do povo quilombola que reside no quilombo. A falta de profissional, de salas de aulas, dentre outros recursos, é claramente um descaso do poder público. Em consequência dessa negligência do Estado, não restou outra alternativa para esta população, a não ser o prejuízo de ter sua escola retirada do local, que ficava dentro da comunidade. Para eles, ter uma escola dentro de suas terras, seria uma vitória gloriosa, visto que dessa forma poderiam manter suas raízes e culturas em um ambiente familiar. Segue dessa forma, um recorte do relatório da pesquisa feita pelas autoras Cristiane Maria Ribeiro e Mariana Cunha Pereira: 


\begin{abstract}
A Comunidade do Cedro contava com uma pequena escola que oferecia a primeira fase do ensino fundamental. As aulas eram ministradas por uma única professora em uma única sala de aula para todos os alunos. A comunidade, mesmo afirmando que a qualidade da educação oferecida era ruim, preferia a comodidade de ter uma escola dentro da área, evitando o deslocamento para a cidade. Hoje essa escola está desativada e a Comunidade frequenta as escolas estaduais e municipais no município de Mineiros. Algumas famílias vivem hoje na cidade por conta do trabalho e também da escola, diminuindo a quantidade de famílias presentes na região do Cedro. (Relatório parcial da visita de campo realizada em set./2010)" (RIBEIRO; PEREIRA, 2016, p. 267)
\end{abstract}

Temos, portanto, que não adianta o governo criar as leis, fazer seus discursos, se não poderão ser aplicados de maneira digna, coesa e eficaz. O Brasil é realmente campeão em publicar decretos e leis, no entanto, estes, acabam apenas fazendo parte de uma somatória de texto infrutífero. E a própria Lei de Diretrizes Curriculares Nacionais para a Educação das Relações Étnico-Raciais e para o Ensino de História e Cultura Afrobrasileira e Africana afirma que "o sucesso das políticas públicas de Estado [...] depende necessariamente de condições físicas, materiais, intelectuais e afetivas favoráveis para o ensino e para aprendizagens". (BRASIL, DCNs, 2004, p. 13).

Logo, com base em tudo que foi exposto até o presente momento, pode concluirse que alguns projetos de ações afirmativas em prol da comunidade negra foram ora frustrados por conta do não cumprimento das leis, ou porque o próprio órgão legislativo não criou as condições estruturais para que as normas pudessem garantir o sucesso dessas políticas públicas. Em vista disso, evocamos as palavras mencionadas no texto da Lei de Diretrizes Curriculares:

Há necessidade, [...] de professores qualificados para o ensino das diferentes áreas de conhecimentos e, além disso, sensíveis e capazes de direcionar positivamente as relações entre pessoas de diferentes pertencimentos étnicoracial, no sentido do respeito e da correção de posturas, atitudes, palavras preconceituosas. Daí a necessidade de se insistir e investir para que os professores, além de sólida formação na área específica de atuação, recebam formação que os capacite não só a compreender a importância das questões relacionadas à diversidade étnico-raciais, mas a lidar positivamente com elas e, sobretudo criar estratégias pedagógicas que possam auxiliar a reeducá-las. (BRASIL, DCNs, 2004, p. 17).

Levando-se em consideração toda a problemática da complexibilidade das normas instituídas no Brasil, é que surge dúvida sobre o efetivo interesse do Estado em proporcionar verdadeiramente a igualdade social. Segundo Domingues (2005, p. 171) Existem algumas correntes de pensamentos que acreditam que "o 'problema' do negro 
será resolvido, simplesmente, com a implementação de políticas públicas universais, quais sejam, programas governamentais que atacariam as causas sociais da desigualdade". No entanto, já vimos que as ações do governo só terão resultados eficazes quando começar cuidando da raiz do problema.

Em vista disso, como já foi exposto antes, e pegando como fundamento o problema da comunidade do Cedro, onde teve sua escola desabilitada devido à falta de estruturas, entende-se que, nesse caso, embora a Lei no 10.639, de 9 de janeiro de 2003, designa a reafirmação da identidade da comunidade afro-brasileira, isso não é possível sem que o Poder Público cuide em levar primeiramente o ensino de qualidade dentro de suas terras. Dessa forma, "todos os alunos negros e não negros, bem como seus professores, precisam sentir-se valorizados e apoiados". (BRASIL, DCNs, 2004, p. 13).

A vista disso, talvez um dos grandes problemas que é frequentemente debatido por várias correntes de pensamentos, tanto da na área da Educação, quanto do Direito, são as cotas raciais. Acreditamos que a crítica acerca da questão de cotas é pontualmente no sentido que o governo faz manobra a seu favor, investindo no ensino superior para criar uma imagem de "santo protetor", porém, na prática não funciona assim. Segundo Domingues (2005, p. 170), a "solução para as distorções raciais na educação é a melhoria do ensino fundamental e médio da rede pública". Contudo, felizmente, mesmo de forma imperfeita, e recebendo críticas de várias partes, as cotas já puderam mudar a vida de muitas pessoas, que talvez sem esta política afirmativa não teriam oportunidade de ingressar em um curso superior. Pois, sabe-se que o ensino básico (fundamental e médio), das escolas públicas não oferece às mesmas oportunidades das escolas de alto padrão. "As cotas são uma alternativa emergencial, provisória, ao passo que a melhoria da rede pública de ensino exige um esforço de médio a longo prazo, ciclo de uma geração, no mínimo" (DOMINGUES, 2005, p. 170).

A propósito, sobre o ensino, educar as crianças no sentido de respeitar as diferenças sociais, tanto raciais como de gênero, não é somente uma obrigação é uma escolha, uma escolha de enriquecimento como ser humano para toda a vida das crianças, e isso cabe primeiramente aos familiares através da educação informal, e posteriormente ao Estado, na educação formal. Entretanto, o Estado tem seu papel de interferir na educação, na busca de garantir a paz da sociedade.

A relevância do estudo de temas decorrentes da história e cultura afrobrasileira e africana não se restringe à população negra, ao contrário, diz 
respeito a todos os brasileiros, uma vez que devem educar-se enquanto cidadãos atuantes no seio de uma sociedade multicultural e pluriétnica, capazes de construir uma nação democrática. (BRASIL. DCNs, 2004, p. 17).

Desse modo, em face da realidade do atual momento em que vivemos, onde o mundo está em constante mudança, e muitas famílias ainda não conseguem acompanhar esta nova modernidade, surge o papel do Estado como pacificador social. "É nas respectivas matrizes curriculares que as possibilidades de realização de uma verdadeira ‘justiça cognitiva' podem ser alcançadas” (ARAÚJO; NAZARENO, 2013, p. 269). Pensando nesse contexto, o Conselho Nacional de Educação ao elaborar as diretrizes curriculares tratou-se de trazer a história do povo afro-brasileiro pontuando os seguintes ensinamentos:

\begin{abstract}
à diversidade étnico-cultural da comunidade; as realidades sociolinguísticas, os conteúdos curriculares que contemplem a história e a realidade quilombola e os modos próprios de constituição do saber e da cultura quilombola; e a participação da respectiva comunidade e do movimento quilombola (CONAE, 2011, p. 30).
\end{abstract}

Ainda tratando dos projetos pedagógicos das escolas, apesar dos avanços no sentido de

\begin{abstract}
Pensar em uma educação quilombola pressupõe, em primeiro lugar, reconhecer o papel determinante de suas formas de saber como estruturantes não apenas de suas formas de vida e de resistência, mas, sobretudo, como constituintes também dos outros saberes e das formas de vida que fazem parte da construção da sociedade brasileira. Neste caso, é preciso pensar um currículo escolar que desconstrua a ideologia da supremacia da cultura ocidental sobre as culturas subalternizadas (ARAÚJO; NAZARENO, 2013, p. 269).
\end{abstract}

Por fim, apesar de todas as críticas mencionadas a respeito das ações afirmativas, sabemos que mesmo que elaboradas de forma, talvez não muito bem pensadas, não deixam de causar um impacto na vida social daqueles que, de certa forma, foram favorecidos em algum momento devido sua origem étnica. Nesse mesmo sentido as autoras Marta, Vanessa e Letícia no $5^{\circ}$ Simpósio da Faculdade de Ciências Sociais da UFG explicam:

As ações afirmativas trouxeram um respiro na educação superior com entrada de outros sujeitos com corpos e saberes que diferem da branquitude, portanto, as diferenças não promoveram uma inserção dos conhecimentos nas grades curriculares eurocentradas e apesar dos avanços da lei 10.639 e, posteriormente a Lei 11.645 que orienta o ensino da cultura afro-brasileiras e indígenas em 
todas as esferas de ensino de forma positivada para o combate da discriminação os cursos na sua maioria disponibiliza uma ou outra disciplina para cumprimento do protocolo (QUINTILIANO; OLIVEIRA e; KRAHÔ, 2019, p. 4).

Dessa forma, fica evidenciado que somente a criação e homologação de leis não irão resolver definitivamente o problema étnico-racial no Brasil. Elas são fundamentais, porém, faz-se necessário vontade política da sociedade brasileira em resolver a problemática e fazer opção e investimento na formação e qualificação dos profissionais que ministrarão os conteúdos implicados nas Leis 10.639 e 11.645 .

\section{Considerações}

Em virtude de todos os fatos mencionados, a relevância do estudo de temas decorrentes da história e cultura afro-brasileira e africana não se restringe à população negra, pois sabemos que os quilombos fazem parte da construção da sociedade brasileira.

No entanto, ainda hoje existe uma batalha a ser conquistada pela comunidade afrobrasileira, que busca seu espaço na sociedade. E a melhor forma desse "povo" vencer esta luta, é, sem dúvida, através das políticas públicas. Todavia, para que estas funcionem como prevista em seu texto, é preciso que a União, os Estados, Distrito Federal e Municípios disponibilizem recursos, tais como: escolas bem estruturadas, professores qualificados para o ensino das diferentes áreas de conhecimentos, estradas asfaltadas, esgoto, além de atendimento sanitário, dentre outros elementos necessários, próximo às suas terras. A falta desses cuidados para com as comunidades quilombolas que ainda têm suas escolas próprias levam cada vez mais a desativação das mesmas.

Porém, a falta de interesse do poder público é um dos obstáculos que engloba o universo dos quilombolas, e a rotatividade política, com visão retrógada, causa prejuízo, ainda maiores, como por exemplo é o que está ocorrendo atualmente, onde o atual presidente congelou a titulação das terras quilombolas.

Logo, o que foi observado ao longo deste é que a falta de organização em aplicar as normas própria e as políticas afirmativas, causa brechas na lei, e a maioria das escolas para atender as medidas imposta pelo Estado disponibiliza uma ou outra disciplina para cumprimento do protocolo.

A partir do que expomos ao longo do texto será muito difícil manter a tradição cultural das comunidades quilombolas, pois, além de todas essas falhas técnicas, existe 
ainda o negacionismo da sociedade em aceitar os "favorecimentos" do Estado para este grupo. Entretanto, o melhor caminho para a paz é a aplicação das políticas afirmativas de forma pedagógica em toda sociedade.

\section{REFERÊNCIAS}

ARAÚJO, Martins Alexandre; NAZARENO, Elias. Interculturalidade, Complexidade Ambiental e Educação Quilombola. CEGRAF UFG. 2013. Cap. 9, p. 269.

BRASIL. CONSELHO NACIONAL DE EDUCAÇÃO - CÂMARA DA EDUCAÇÃO BÁSICA. Texto - referência para a elaboração das Diretrizes Curriculares Nacionais para a Educação Escolar Quilombola. Brasília, 2011.

BRASIL. Diretrizes Curriculares Nacionais para a Educação das Relações ÉtnicoRaciais e para o Ensino de História e Cultura Afro-brasileira e Africana. Brasília (DF). Outubro, 2004, p. 13.

COMISSÃO PRO-ÍNDIO DE SÃO PAULO. Governo Bolsonaro caminha para segundo ano consecutivo sem titular Terras Quilombolas. Disponível em: https://cpisp.org.br/governo-bolsonaro-caminha-para-segundo-ano-consecutivo-semtitular-terras-quilombolas/. Acessado em: 03/12/2021.

DOMINGUES, Petrônio. Ações afirmativas para negros no Brasil: o início de uma reparação histórica. Espaço Aberto. Maio /jun. /Jul /ago. 2005 No 29. P. 171.

FREITAS, Daniel Resende; LUCIANO, Daniela Freitas e; SILVA, I. de Fátima. Quilombo Cedro - Mineiros (GO): um estudo sobre a formação cultural e posse da terra. V Colóquio Estadual de Pesquisa Multidisciplinar- III Congresso Nacional de Pesquisa Multidisciplinar e II Feira de Empreendorismo da Unifimes. 2021.

MUNANGA, Kabengele. Por que ensinar a história da África e do negro no Brasil de hoje? Revista do Instituto de Estudos Brasileiros, Brasil, n. 62, p. 20-31, dez. 2015.

QUINTILIANO, Marta; OLIVEIRA, Vanessa Fonte de; KRAHÔ, Letícia Jôkàhkwyj. Epistemologias que curam: por conhecimentos Indígenas, negras e Quilombolas na Universidade Federal de Goiás. $5^{\circ}$ Simpósio da Faculdade de Ciências Sociais- UFG. Campos Samambaia, Goiânia- Brasil. 11 a 13 de setembro de 2019, P. 4.

RIBEIRO, C. M. As pesquisas sobre o negro e a educação no Brasil: uma análise de suas concepções e propostas. UFSCAR: SÃO Carlos; SP2005. (Tese de doutorado).

RIBEIRO, Maria Cristiane; PEREIRA, Cunha Mariana. As escolas quilombolas em Goiás - retrato da escola na relação com o poder público dos anos 2000. Polyphonía, v. 27/1, jan./ jun. 2016, p. 267. 
SECRETARIA DE ESTADO DE DESENVOLVIMENTO SOCIAL. Governo do Estado de Goiás. Disponível em: https://www.social.go.gov.br/noticias/166-governocondecora-personalidades-com-comenda-zumbi-dos-

palmares.html?highlight=WyJnb2lcdTAwZTFzliwicXVpbG9tYm9sYSJdpalmares.html ?highlight=WyJnb2lcdTAwZTFzLiwicXVpbG9tYm9sYSJd. Publicado: 20 novembro 2019. Acessado em: 03/12/201.

Recebido em: 20/11/2021

Aprovado em: 15/12/2021

Publicado em: 17/12/2021 